\title{
Comparative study of spark plasma sintering features on the densification of $\mathrm{Ni}-\mathrm{Cr}$ binary alloys
}

\author{
B J Babalola ${ }^{1}$, M B Shongwe ${ }^{1}$, B A Obadele², P A Olubambi², O O Ayodele ${ }^{2}$, A L Rominiyi ${ }^{1}$ and S O Jeje ${ }^{1}$ \\ 1 Institute of NanoEngineering Research Institute, Department of Chemical, Metallurgical and Materials Engineering, Faculty of \\ Engineering and Built environment, Tshwane University of Technology, Pretoria, South Africa. \\ ${ }^{2}$ Center for NanoEngineering and Tribocorrosion, School of Mining, Metallurgical and Chemical Engineering, University of Johannesburg, \\ Doornfontein Campus, 2028 Johannesburg, South Africa.
}

\begin{abstract}
Spark plasma sintering (SPS) has been widely regarded as an advanced powder consolidation technique which helps in the development of array of engineering materials. Many have been reported in the literature about sintering parameters such as temperature, pressure, heating rate and holding time. However, little or no reports has been made on some of the intricate features such as process time(s), power SPS $(\mathrm{KW})$, pressing speed $(\mathrm{mm} / \mathrm{min})$, and average pressing force $(\mathrm{KN})$ on which sintering parameters are directly related to. This study aims to investigate the behaviour of spark plasma sintered $\mathrm{Ni}-17 \mathrm{Cr}$ binary alloys with emphasis on the densification, hardness value and spark plasma sintering features such as process time (s), power SPS (KW), pressing speed $(\mathrm{mm} / \mathrm{min})$, and the average pressing force $(\mathrm{KN})$. Nickel and chromium powders were milled individually using High energy ball milling for durations of $5 \mathrm{hr}, 10 \mathrm{hr}$ prior to mixing and subsequent sintering. The sintered $5 \mathrm{hr}$ and $10 \mathrm{hr}$ milled Ni-17Cr binary alloys attained relative densities of $98.72 \%$ and $99.1 \%$ respectively. The Microstructural morphology was examined using Scanning electron microscopy (SEM). The sintered $10 \mathrm{hr}$ milled $\mathrm{Ni}-17 \mathrm{Cr}$ binary alloy revealed the higher hardness.
\end{abstract}

\section{INTRODUCTION}

Spark plasma sintering (SPS) utilizes the principle of pressure assisted powder consolidation under the influence of low voltage pulsed electric current within a graphite die [1, 2]. Fundamental behaviour of SPS process entails firstly; propagation and effect of local electric plasma discharge on mass and heat transport in compacted body, secondly; the effect of external force coupled with electric on densification and phase evolution within the compact material, and thirdly; the effect of electric current in the near surface layers of semiconductive, dielectric and conductive materials [3] at elevated temperatures; and (4) occurrence of temperature gradient due to rapid and no uniform heating/cooling within the material [4]. SPS employs uniaxial load coupled with high-power electrical circuit positioned in a controlled atmosphere (Figure 1) [5]. The pulse voltage and current generates spark discharges and joule heat regions between the surfaces of the particles, this develop into heat transfer and distribution through the material and consequently resulting into high homogeneity and uniform densities. The technique helps to prevent limitations such as microsegregation, excessive grain growth, and long and complex processing duration when compared to other processing routes $[3$,
6]. The spark generated between the particles surfaces helps to clean the surfaces and impurities present and subsequent melting of the surfaces of the particles. The liquid state surfaces are drawn towards each other via electron draw, thereby creating "necks". The necks develop gradually and increases due to the continuous joule heating coupled with pressure.

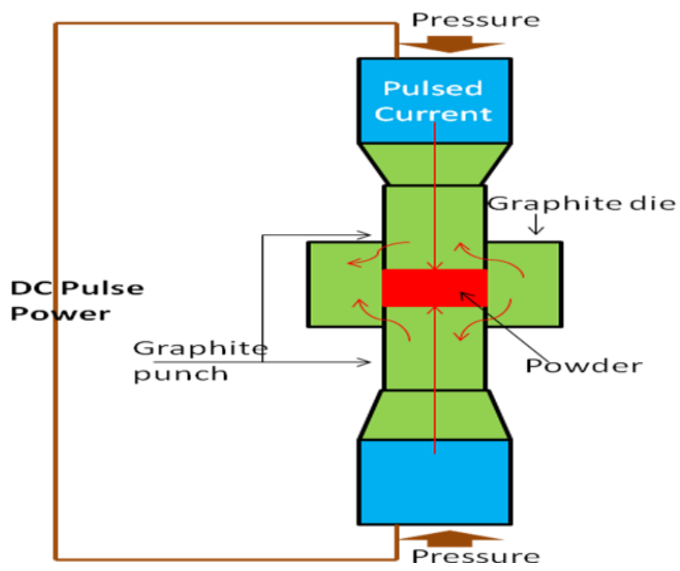

Figure 1: Schematic diagram showing SPS working process

The heat generated all through the SPS process is centralized on the materials particle surfaces. However, 
due to high speed at which SPS attains completion of its process coupled with the fact that the surface temperature of the particles rises rapidly, grain growth are limited [3, $7,8]$. Adequate control of SPS parameters helps to ensure highly dense sintered products and also the ability to prevent little or no grain growth. Force (pressure) control is significant in achieving this role as the material moves under pressure. Nevertheless, clear understanding of trend of spark plasma sintering machine power usage, pressing speed of the punches, and pressing force utilized by the process over the total process time is necessary under prevailing set sintering parameters.

\section{METHODOLOGY}

Nickel powders (4-7 $\mu \mathrm{m}, 99.8 \%$ purity), Chromium powders (10 $\mu \mathrm{m}, 99.2 \%$ purity) supplied by Goodfellow Metals and Wear Tech (PTY) LTD respectively were milled individually for intervals of $5 \mathrm{hr}$ and $10 \mathrm{hr}$ using high energy planetary ball milling (Retsch PM-400). The milling operation was carried out at constant milling speed of $300 \mathrm{rev} / \mathrm{min}$, milling interval of $2 \mathrm{hr}$ and interval break of 15 mins. Stainless steel vial and balls of $250 \mathrm{ml}$ and $2 \mathrm{~mm}$ diameter were used respectively with the aid of ethanol as process control agent (PCA). The milled powders were dried after subsequent milling using Vacutech drier. After drying, nickel and chromium powders milled for $5 \mathrm{hr}$ and $10 \mathrm{hr}$ were mixed according to their stoichiometric ratio $(83 \mathrm{wt} \% \mathrm{Ni}-17 \mathrm{wt} \% \mathrm{Cr}$ ) for 8 hr separately. These results into two separate mixes, which are (i) Ni-17Cr binary alloy, $5 \mathrm{hr}$ milled, and (ii) $\mathrm{Ni}-17 \mathrm{Cr}$ binary alloy at $10 \mathrm{hr}$ milled. The binary combinations were mixed to attain homogeneity and were sintered by spark plasma sintering (HHPD-25, FCT Systeme $\mathrm{GmbH}$ ) at sintering temperature of $1100^{\circ} \mathrm{C}$, heating rate of $150^{\circ} \mathrm{C} / \mathrm{min}$, holding time of $5 \mathrm{~min}$ and pressure of $50 \mathrm{MPa}$.

The sintered samples were sand blasted to remove remains of graphite foils. The density was evaluated thereafter using Archimedes principle while the immersion liquid is distilled water. The sintered samples were cut and prepared for metallographic examination with strict adherence to standard procedures. They were characterized with the aid of X-Ray diffraction (XRD) employing the PANalytical Empyrean model with $\mathrm{Cu} \mathrm{K} \alpha$ radiation. The polished cross-section was etched using Marble's reagent $\left(50 \mathrm{ml} \mathrm{HCl}, 50 \mathrm{ml} \mathrm{H}_{2} \mathrm{O}\right.$, and $10.0 \mathrm{gm}$ $\mathrm{CuSO}_{4}$ ) to investigate the internal microstructure. SEM investigation were carried out on JEOL, JSM-7600F, Japan, equipped with an EDX detector (Oxford X-Max) with INCA X-Stream2 pulse analyzer software, and Back Scattered Electron (BSE) detectors. Vickers microhardness indenter (Future-tech) with a fixed load of $100 \mathrm{gf}(1.0 \mathrm{~N})$ was applied at a holding time of $10 \mathrm{~s}$. The average of ten indents was taken for the hardness value for consistency in Vickers microhardness scale (HV).

\section{RESULTS AND DISCUSSIONS}

\subsection{Microstructural analysis of starting and milled powders}

The Scanning electron microscopy- secondary electron images are shown in Figure 2. As shown in Figure 2: (a) represent the as receive chromium powder which is characterized by acicular shapes as shown in red scribble, flake oriented particles was observed when milled for 5 $\mathrm{hr}$ (Figure 2b) and more was observed at milling duration of $10 \mathrm{hr}$ (Figure 2c) as indicated by white arrows. The asreceived nickel powder (Figure 2d) shows characteristic spiky and feathery oriented shape as indicated by dark arrows, milling operation enables the nickel powder to deform into plate like particles as shown in dark blue ribbon (Figure 2e-f). The changes in the shape of the powders from their initial state was as a result of the deformation process impacted on it by the vials and milling balls during the milling operation

\subsection{Density and hardness value}

The density evaluation reveals that the $\mathrm{Ni}-17 \mathrm{Cr}$ alloy $(5$ $\mathrm{hr}$ milled) and $\mathrm{Ni}-17 \mathrm{Cr}$ alloy (10 hr milled) have relative densities of $98.72 \%$ and $99.1 \%$ respectively (Table 1 ). The Ni-17Cr alloy (10 hr milled) attains higher hardness value; this can be attributed to its low level of porosity as it is highly dense. The increased density of the alloy can be attributed to the effect of milling operation in which the nickel and chromium powder attained reduced crystalline size. The nickel powder attained crystallitesize of $78.67 \AA$ and $82.07 \AA$ after $10 \mathrm{hr}$ and $5 \mathrm{hr}$ milling respectively.

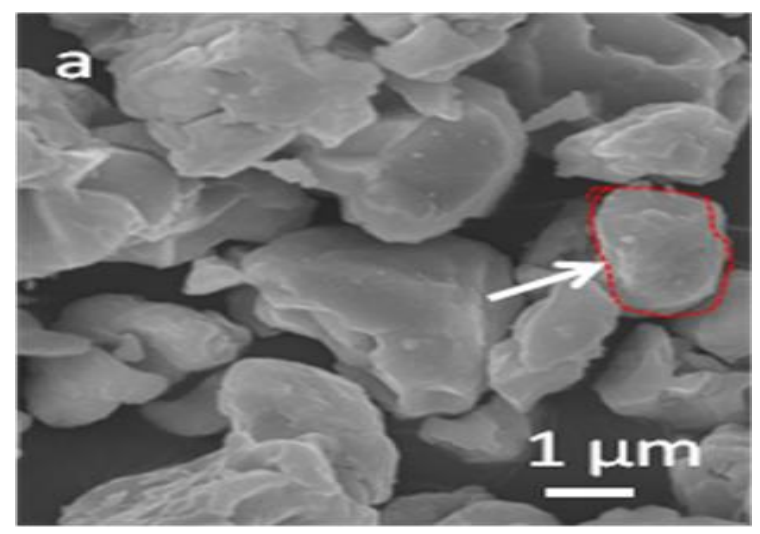



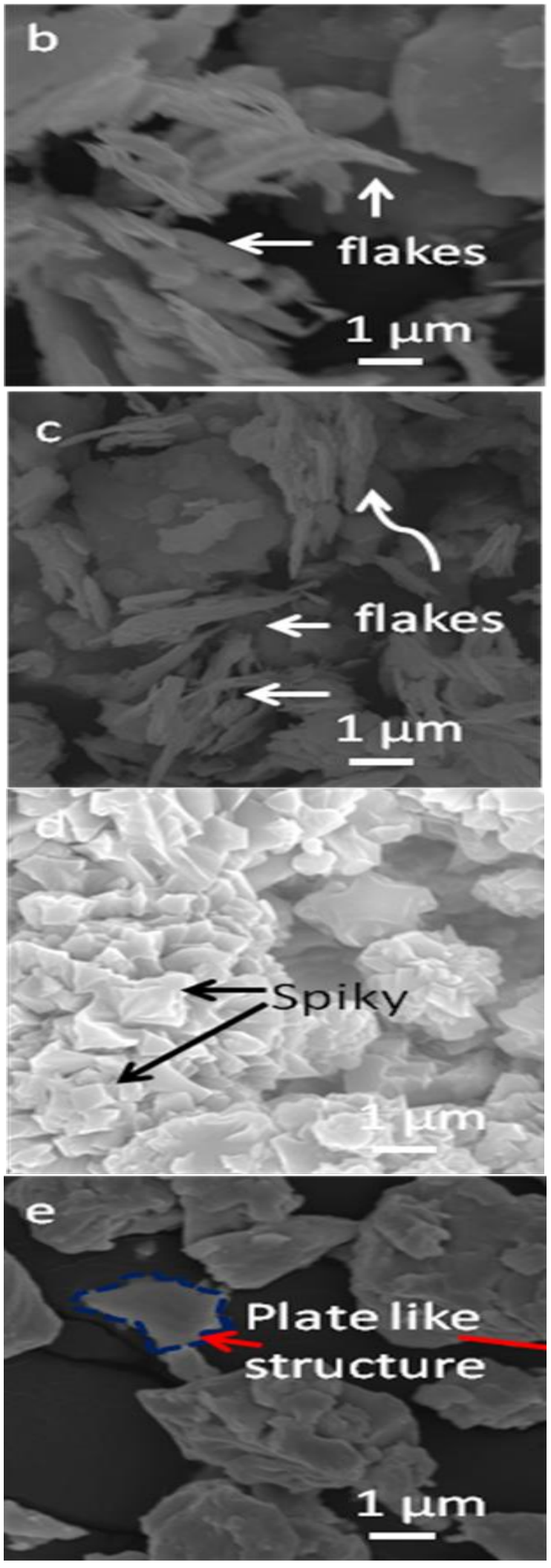

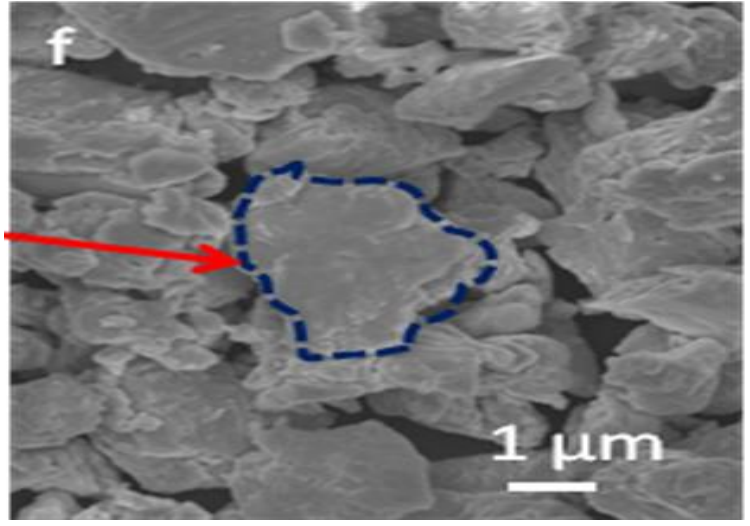

Figure 2: SEM SE images of (a) pure chromium, (b) chromium powder milled for $5 \mathrm{hr}$, (c) chromium powder milled for $10 \mathrm{hr}$, (d) pure nickel, (e) nickel powder milled for $5 \mathrm{hr}$, and (f) nickel powder milled for $10 \mathrm{hr}$.

As a result of these trend, it can be deduced that the density and hardness of the alloys increases with increasing milling time.

Table 1. Relative density and Hardness values of sintered alloy.

\begin{tabular}{|c|c|c|c|}
\hline Sample & $\begin{array}{c}\text { Relative } \\
\text { Density } \\
(\%)\end{array}$ & $\begin{array}{c}\text { Porosity } \\
(\%)\end{array}$ & $\begin{array}{c}\text { Hardness } \\
\text { Value (HV } 1.0)\end{array}$ \\
\hline $\begin{array}{c}\text { Ni-17Cr (5 } \\
\text { hr milled) }\end{array}$ & 98.72 & 1.28 & 291 \\
\hline $\begin{array}{c}\text { Ni-17Cr (10 } \\
\text { hr milled) }\end{array}$ & 99.1 & 0.9 & 337 \\
\hline
\end{tabular}

\subsection{Microstructure and phase analysis of Sintered Sample}

The SEM morphology revealed even distribution of elemental composition and also the presence of porosity as indicated by red scribble (Figure $3 a-b$ ). The Energy Dispersive X-Ray analysis (EDX) as shown in Figure 3 confirms the elements present in the alloy as indicated by the intensity of the peaks. As shown in Fig. 3c, there were no other phases formed in the sintered alloy from the XRD results. As can be seen from Figure 3, milling operation which enables size reduction of elements helps to attain improved densification. Reduction in the size via milling operation brings about pore reduction, and strong metallurgical and consequent increase in hardness.

\subsection{Trend of Spark plasma sintering features in relation to densification}

Spark plasma sintering features such as power usage $(\mathrm{KN})$, pressing speed of the punches $(\mathrm{mm} / \mathrm{min})$ and pressing force $(\mathrm{KN})$ were discussed with respect to the overall processing time for individual sintering of the alloys. Lower SPS power was utilized by Ni-17Cr $(10 \mathrm{hr}$ milled) to attain the set maximum sintering temperature as it can be seen from Figure 4. This can be attributed to the effect of milling operation which resulted into the reduction of the initial particle. As a result of the milling 
effect, the energy required for consolidation reduces. The power utilized during the holding time ranging from 557 $\mathrm{s}$ to $855 \mathrm{~s}$ was observed to be constant and lower to that to attain the maximum temperature. Higher pressing speed was observed for the $10 \mathrm{hr}$ milled sintered alloy (Figure 5a), this as a result of the reduced crystalline size which enables it to further reduce porosity and increased densification compared to the $5 \mathrm{hr}$ sintered alloy. It was observed that significant part of the pressing speed was carried out during heating up of the samples.

Force applied to enhance densification of the alloys was observed to be active from heating till end of the holding time at maximum temperature (Figure $5 \mathrm{~b}$ ).

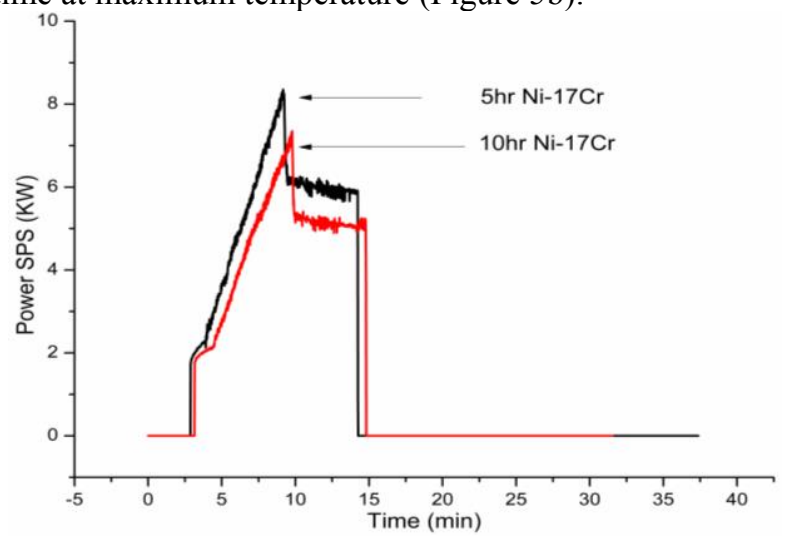

Figure 4: Power SPS (KW) against Process Time (s) of the sintered alloy
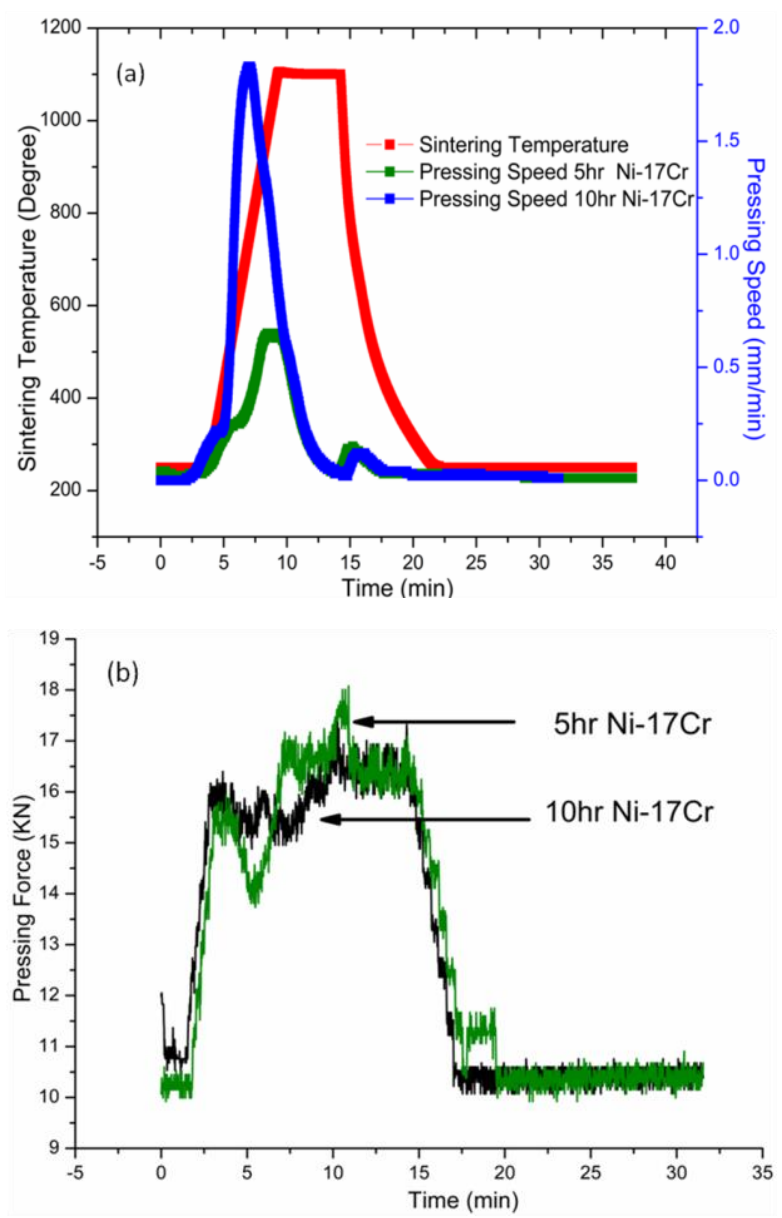

Figure 5: (a) Power Speed ( $\mathrm{mm} / \mathrm{min})$ and sintering temperature against Process Time (s) of the sintered alloy, (b) Pressing force $(\mathrm{KN})$ against Process Time (s)

\section{Conclusion}

Nickel and chromium powder was milled individually for durations of $5 \mathrm{hr}$ and $10 \mathrm{hr}$. Nickel powder attained a crystalline size of $78.67 \AA$ at the $10 \mathrm{hr}$ milling as against $82.07 \AA$ at $5 \mathrm{hr}$. The binary alloy was sintered at a sintering temperature of $1100{ }^{\circ} \mathrm{C}, 50 \mathrm{MPa}$, and a heating rate of $150{ }^{\circ} \mathrm{C} / \mathrm{min}$. The sintered alloy attained relative densities of $98.72 \%$ and $99.1 \%$ for Ni-Cr ( $5 \mathrm{hr}$ milled) and, $\mathrm{Ni}-\mathrm{Cr}$ (10 hr milled) respectively, and were observed to increase as the milling time increases. The study shows that SPS utilizes lower power to attain the maximum sintering temperature where lower particle sizes are used. Higher pressing speed was also recorded for lower particle/crystalline size powders obtained via milling process, which implies high densification.

\section{Acknowledgements}

The authors would like to extend appreciation to National Research Foundation of South Africa for the grant, Unique Grant No. 99348. Research facilities support by the Center for NanoEngineering and Tribocorrosion, School of Mining, Metallurgical and Chemical Engineering, University of Johannesburg, Doornfontein Campus, 2028 Johannesburg, South Africa, and Institute for NanoEngineering Research, Department of Chemical, Metallurgical and Materials Engineering, Faculty of Engineering and Built Environment, Tshwane University of Technology, Pretoria, South Africa.

\section{References}

1. Guillon, O., et al., Field-assisted sintering technology/spark plasma sintering: mechanisms, materials, and technology developments. Advanced Engineering Materials, 2014. 16(7): p. 830-849.

2. Suárez, M., et al., Challenges and opportunities for spark plasma sintering: a key technology for a new generation of materials, in Sintering Applications. 2013, InTech.

3. Shinohara, T., et al., Densification process in fabrication of PSZ-Ti composites by spark plasma sintering technique. Materials Characterization, 2017. 132(Supplement C): p. 230-238.

4. Ragulya, A.V., Fundamentals of Spark Plasma Sintering, in Reference Module in Materials Science and Materials Engineering. 2016, Elsevier.

5. Dong, X., et al., Influence of spark plasma sintering temperature on electrochemical performance of LaO. $80 \mathrm{Mg}$ 0. 20Ni3. 75 alloy. Materials Chemistry and Physics, 2008. 112(2): p. 596-602.

6. Shongwe, M.B., et al., Effect of sintering temperature on the microstructure and mechanical properties of $\mathrm{Fe}-30 \% \mathrm{Ni}$ alloys produced by spark 
plasma sintering. Journal of Alloys and Compounds, 2015. 649(Supplement C): p. 824-832.

7. Bahrami, S., et al., Spark plasma sintering of silicon nitride/barium aluminum silicate composite. Ceramics International, 2017. 43(12): p. 9153-9157.
8. Stanciu, C.A., et al., Lanthanum influence on the structure, dielectric properties and luminescence of BaTiO3 ceramics processed by spark plasma sintering technique. Journal of Alloys and Compounds, 2017. 706(Supplement C): p. 538-545.
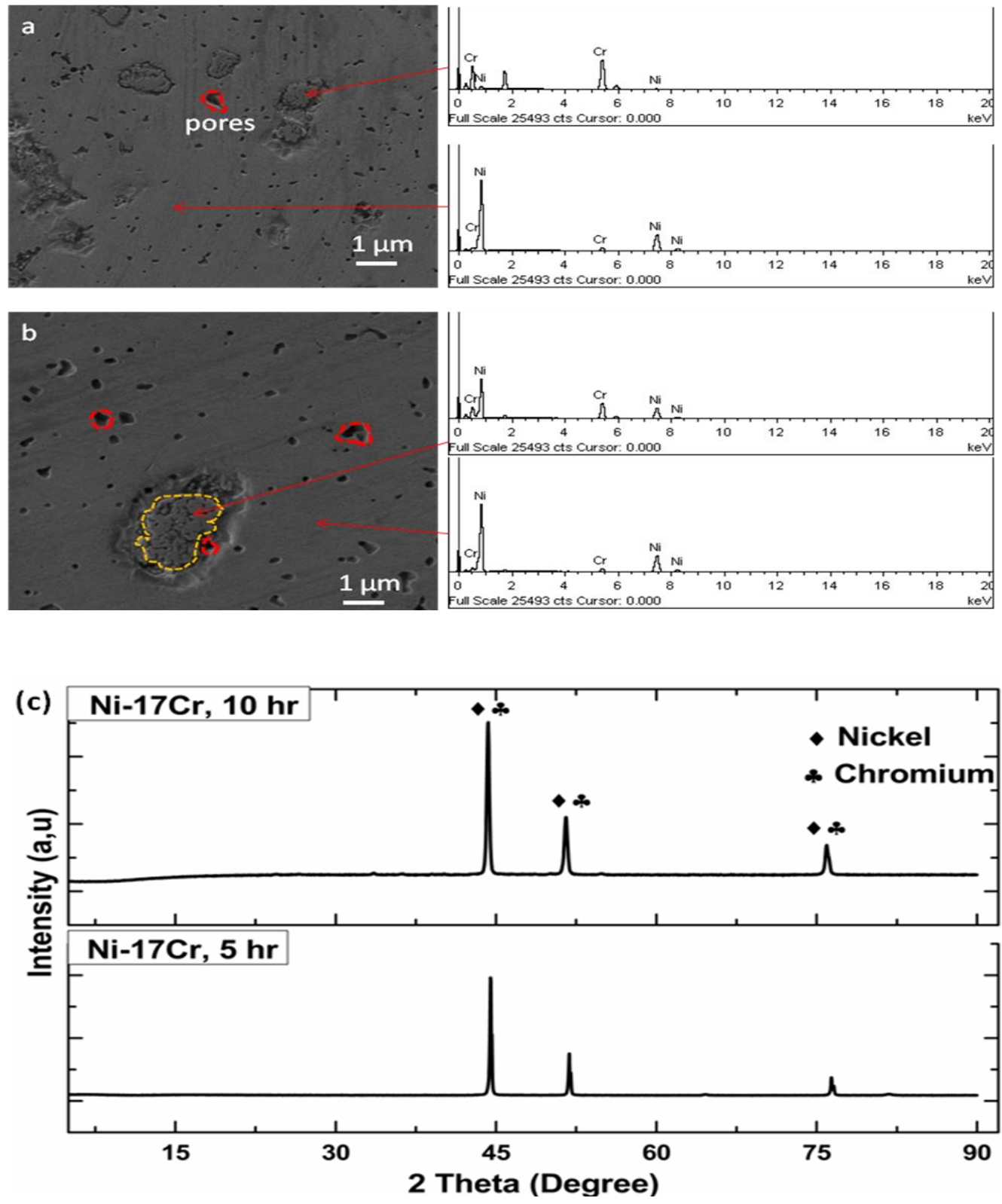

Figure 3. SEM SE image and EDX of sintered alloys (a) Ni-17Cr, $5 \mathrm{hr}$ milled, and (b) Ni-17Cr, $10 \mathrm{hr}$ milled, and (c) XRD pattern of sintered alloys. 